\title{
Caracterização das lesões inflamatórias em corações bovinos comercializados em açougues da cidade de Nova Friburgo, RJ
}

\author{
Inflamatory lesions characterization of the bovine hearts traded in local \\ butcher shop in Nova Friburgo city, RJ
}

Renata Falcão Rabello da Costa, ${ }^{*}$ lacir Francisco dos Santos, ${ }^{* *}$ Elmiro Rosendo do Nascimento, ${ }^{* * *}$ Rogerio Tortelly****

\begin{abstract}
Resumo
Foram estudados, através da técnica de Santos e do fatiamento, 240 corações de bovinos adquiridos em açougues da cidade de Nova Friburgo, RJ, com o objetivo de caracterizar as lesões inflamatórias. Amostras com e sem lesões aparentes, do tipo cística, nodular ou difusa, focais, esbranquiçadas e/ou amareladas, fixadas em formol a 10\%, foram processadas pela técnica habitual de inclusão em parafina e coradas pela hematoxilina-eosina (HE). Foram observadas lesões císticas por Cysticercus bovis vivo e, nodulares, por morto, sendo este último preponderante. O exame microscópico dos cisticercos mortos revelou, de uma forma geral, lesões granulomatosas centralizadas por material caseoso e/ou calcário, células gigantes multinucleadas, histiócitos em paliçada, infiltrado misto, predominantemente de mononucleares, envoltos por cápsula fibrosa que, por vezes, continha áreas mineralizadas. Rara foi a observação dos corpúsculos calcários. Miocardites inespecíficas multifocais, compostas por elementos celulares mononucleares, associando-se, por vezes, à infiltração gordurosa e fibrose dissociando as miofibras, estiveram presentes em amostras com e sem lesões visíveis, sendo encontradas freqüentemente ao redor de cistos de Sarcocystis sp. Digno de nota foi a intensidade da infecção, impressionante em algumas amostras, e a presença conspícua destes microcistos nas fibras de Purkinje.
\end{abstract}

Palavras-chave: bovino, Cysticercus bovis, Sarcocystis sp., coração, miocardite, inspeção sanitária.

\begin{abstract}
Aiming the characterization of inflammatory lesions, 240 bovine hearts were examined using the Santos and slicing techniques. The hearts were obtained at local butcher shop in Nova Friburgo/RJ city. Samples with and without visible lesions, such as cysts, nodules or diffuse, focal, whitish ones, fixed in $10 \%$ formalin were submitted for histological examination, being routinely processed and stained with hematoxylin and eosin (HE). Cysticerci was found in viable and degenerated condition, being the last one predominant. In a general way, the histological exam of the degenerate cysticerci revealed granulomatous lesions, whose centers were characterized by caseous and/or calcareous material, multinucleate giant cells, histiocytes in palisade and infiltrated composed predominantly of lymphoid cells, wrapped up by a fibrous capsule that, some times, contained mineralized areas. Calcareous corpuscles were rare. Foci of non specific myocarditis associated, in some cases, to the fatty and fibrous infiltration, were observed in samples with or without macroscopic lesions and frequently they appeared surrounding the cysts of Sarcocystis sp. In general, it were remarkable the infection degree and the conspicuous presence of such cysts in the Purkinje fibers.
\end{abstract}

Keywords: bovine, Cysticercus bovis, Sarcocystis sp., heart, myocarditis sanitary inspection.

\section{Introdução}

As moléstias inflamatórias do miocárdio comumente são infecciosas. Contudo, existem relatos cuja patogênese permanece obscura, como por exemplo, áreas focais de miocardite, necrose e fibrose do miocárdio, que são observadas, com certa freqüência, particularmente em animais idosos. Ocasionalmente são observadas cicatrizes de tecido fibroso, que são interpretadas como sendo procedentes de um abscesso ou lesão parasitária curada (Jones et al., 2000). Dentre as lesões parasitárias cardíacas de bovinos merecem destaque a Cisticercose e a Sarcosporidiose.

* Programa de Pós-Graduação em Medicina Veterinária (Doutorado) - Higiene Veterinária e Processamento Tecnológico de Produtos de Origem Animal - Faculdade de Veterinária - Universidade Federal Fluminense.

** Departamento de Tecnologia dos Alimentos da Faculdade de Veterinária da Universidade Federal Fluminense. Rua Vital Brazil Filho, 64. Niterói, RJ - CEP 24230-340.

*** Departamento de Medicina Coletiva Veterinária e Saúde Pública da Faculdade de Veterinária da Universidade Federal Fluminense.

**** Departamento de Patologia e Clínica Veterinária - Faculdade de Veterinária, Universidade Federal Fluminense.

Autor para correspondência: Renata Falcão Rabello da Costa. E-mail: rrfalcosta@yahoo.com.br 
O Cysticercus bovis é encontrado com muita freqüência no exame post mortem, sendo o coração considerado, segundo Villanueva e Peraza (1981), Santos (1984), Bundza et al. (1988), Santos (1993), Santos et al. (2001) e Costa et al. (2005), o principal órgão lesado por este metacestóide.

Não há muita dificuldade para o diagnóstico macroscópico do $C$. bovis vivo (íntegro): o cisto é branco-acinzentado, freqüentemente alongado no sentido das fibras musculares, com líquido (às vezes rosado) e um escólex nitidamente visível que pode ser deslocado dentro do cisto, quando pressionado (Santos, 1984). Todavia, o diagnóstico da cisticercose pode ser dificultado nos casos em que as larvas estejam mortas (em lesões abscedadas e mineralizadas), condição esta que diversos autores, tais como Gibson (1959), Santos (1984), Bundza et al. (1988) Santos (1993) e Costa et al. (2005) afirmam ser predominante na rotina de inspeção. Nestes casos, o apoio do exame histopatológico pode ser de grande valia na diferenciação de patologias assemelhadas, como, por exemplo, lesões provocadas pela migração de larvas de helmintos, que não o cisticerco, e até mesmo a tuberculose, conforme descreveram Monlux e Monlux (1972) e Kelly (1997).

Microscopicamente, nessa condição, as lesões se apresentam com centro necrótico circundado por tecido de granulação e intenso infiltrado de polimorfonucleares, sobretudo eosinófilos (Gibson, 1959). Amiotrofia por compressão parasitária pode ser observada (Sterba e Dyková, 1978; Santos, 1984). Mais tardiamente, mononucleares, histiócitos em paliçada, bem como células gigantes multinucleadas organizam-se ao redor dos focos necróticos, por vezes com áreas mineralizadas (Sterba e Dyková, 1978, Bundza et al., 1988; Santos et al., 2001). Sterba e Dyková (1978) ressaltam dois tipos focais de necrose com calcificação distrófica: uma de fibras colágenas, originada no tecido conectivo maduro circunjacente à reação e observada principalmente no coração e fígado, e, a outra, do exsudato. Eles salientam, ainda, que os focos necróticos observados na margem inflamatória são típicos da reação ao $C$. bovis. $A$ partir de estudos comparativos, Sterba et al. (1979) estudaram as reações teciduais ao $C$. bovis no coração, tendo observado maior intensidade na seqüência dos eventos inflamatórios, principalmente no miocárdio.

Estruturas levemente acidófilas, acelulares, bem como corpúsculos calcários podem ser percebidos (Santos, 1984; Bundza et al., 1988; Santos et al., 2001). Os corpúsculos calcários são concreções que aparecem no parênquima de muitas espécies de cestóides, dentre eles a T. saginata, e consistem em uma base orgânica (proteínas, glicogênio e fosfatase alcalina) ligada a materiais inorgânicos, principalmente o cálcio, além do magnésio, fósforo, dióxido de carbono e traços de alguns elementos metálicos (Chowdhury et al., 1962). Às vezes, são a única evidência, mediante a reabsorção do parasita morto, de que o espécime encontrado seja realmente um cestóide.

Jones et al. (2000) citam que, via de regra, a principal alteração tecidual provocada pelo cisticerco vivo é o deslocamento das miofibras. Pode haver discreta miosite, com alguns linfócitos e macrófagos.
Quanto à sarcosporidiose, protozoose causada pelo Sarcocystis sp., a literatura demonstra que a sua prevalência nos bovinos (um de seus hospedeiros intermediários) é muito alta, podendo alcançar taxa superior a 90\% (Acha e Szyfres, 1986), chegando a 100\% (Pereira, 1986; Santana et al., 2003). Observa-se, também, que pode ser um achado freqüente em preparações histológicas de músculo cardíaco (Pereira, 1986; Santana et al., 2003). De um modo geral, essa informação refere-se à sarcosporidiose muscular sem identificação das espécies, que no caso dos bovinos são o $S$. hirsuta $(S$. bovifelis), o S.hominis ( $S$. bovihominis) e o S.cruzi ( $S$. bovicanis), que têm como hospedeiros definitivos, respectivamente, o felino, o homem e o cão (Acha e Szyfres, 1986).

À microscopia, nas fibras musculares cardíacas e esqueléticas, observam-se cistos ovalados, de tamanhos variados, limitados por uma parede que emite septos para o interior, dividindo-os em compartimentos que contêm os bradizoítas elípticos e fortemente basofílicos. Na maioria dos casos, tais cistos são vistos distorcendo as miofibras sem causar reação inflamatória alguma. Contudo, há relatos de estímulos inflamatórios que podem ser, inclusive, granulomatosos (Dubey et al., 1982), por ocasião da ruptura dos mesmos. Pereira (1986) e Jones et al. (2000) fazem menção da localização desses parasitas nas fibras de Purkinje.

\section{Material e métodos}

Foram estudados 240 corações de bovinos adquiridos em açougues da cidade de Nova Friburgo, RJ, inspecionados pela técnica de Santos, seguida do fatiamento, segundo Costa et al. (2005)

Foram considerados como cisticercos vivos (íntegros), os cistos com parede translúcida, contendo um líquido claro e um ponto esbranquiçado no interior: o escólex. Foram reputados como cisticercos mortos aqueles que apresentaram cápsula fibrosa aderente ao tecido circunvizinho, contendo material amarelado caseoso e/ou calcário.

Também foram computadas alterações cardíacas macroscópicas inespecíficas, além, ainda, de terem sido colhidos fragmentos sem lesões visíveis, selecionados, de uma forma geral, de músculos papilares direito e esquerdo, região subendocárdica direita e esquerda, próximas ao vértice e, às vezes aurículas e crista supraventricular.

Todas as amostras foram fixadas em solução de formol a 10\% e remetidas ao Serviço de Anatomia Patológica Veterinária Professor Jefferson Andrade dos Santos, da Universidade Federal Fluminense, com fins histológicos, para processamento habitual de inclusão em parafina e coloração pela hematoxilinaeosina (HE). Em seguida, foram submetidas ao exame em microscopia óptica.

O conteúdo retirado de cistos íntegros, que foram comprimidos entre lâminas de microscopia, dispensou preparações histológicas, sendo levado diretamente ao microscópio óptico. 


\section{Resultados e discussão}

Macroscopicamente, foram diagnosticadas 23 lesões consideradas morfologicamente como C. bovis morto e, três, como vivo.

O exame microscópico revelou a presença de cisticercos vivos (Figura 1), mortos e de granulomas inespecíficos, ricos em elementos linfóides, acompanhados de fibrose em alguns casos.

Dois cistos íntegros, comprimidos entre lâminas, foram identificados como $C$. bovis pela microscopia (Figura 2).

As seções histológicas dos cisticercos mortos estão em consonância com as descrições da literatura, uma vez que, de uma forma geral, revelaram granulomas comumente representados por centro necrótico (Figura 3) e/ou mineralizado envolto por histiócitos dispostos em paliçada, células gigantes multinucleadas e infiltrado inflamatório misto, predominantemente de mononucleares. Observou-se, ainda, fibrose causando amiotrofia por compressão. Por vezes, a cápsula fibrosa tinha características de tecido de granulação e mineralização de aspecto linear (Figura 4). A mineralização linear, bem como os histiócitos em paliçada não são descritos na tuberculose, sendo elementos diferenciais entre tais diagnósticos. Quanto à similaridade microscópica do processo inflamatório crônico concernente a outros helmintos como, por exemplo, a oncocercose e a pentastomíase, conforme mencionaram Monlux e Monlux (1972), o conhecimento de suas distribuições anatômicas, taxa de ocorrência e características macroscópicas podem ser subsídios úteis à diferenciação.

Os restos parasitários foram identificados como um material hialino acelular, contendo elementos ovóides basofílicos, acidófilos e incolores, os corpúsculos calcários (Figura 5). Entretanto, esses corpúsculos foram raros nessas lesões, tendo sido vistos em apenas duas. Uma delas tinha o centro totalmente mineralizado (Figura 6), sendo comparável à citação de Bundza et al. (1988). Ao contrário da citação de Gibson (1959) e Santos et al. (2001), observou-se uma quantidade variada de eosinófilos, sendo, porém, escassos. Tendo em vista o caráter crônico das lesões admite-se que a observação dos elementos característicos esteja vinculada ao grau de reabsorção do cisticerco, pois, segundo Monlux e Monlux (1972), Sterba e Dyková (1978) e Sterba et al. (1979), com a morte do parasita, haveria a fagocitose de seus restos por

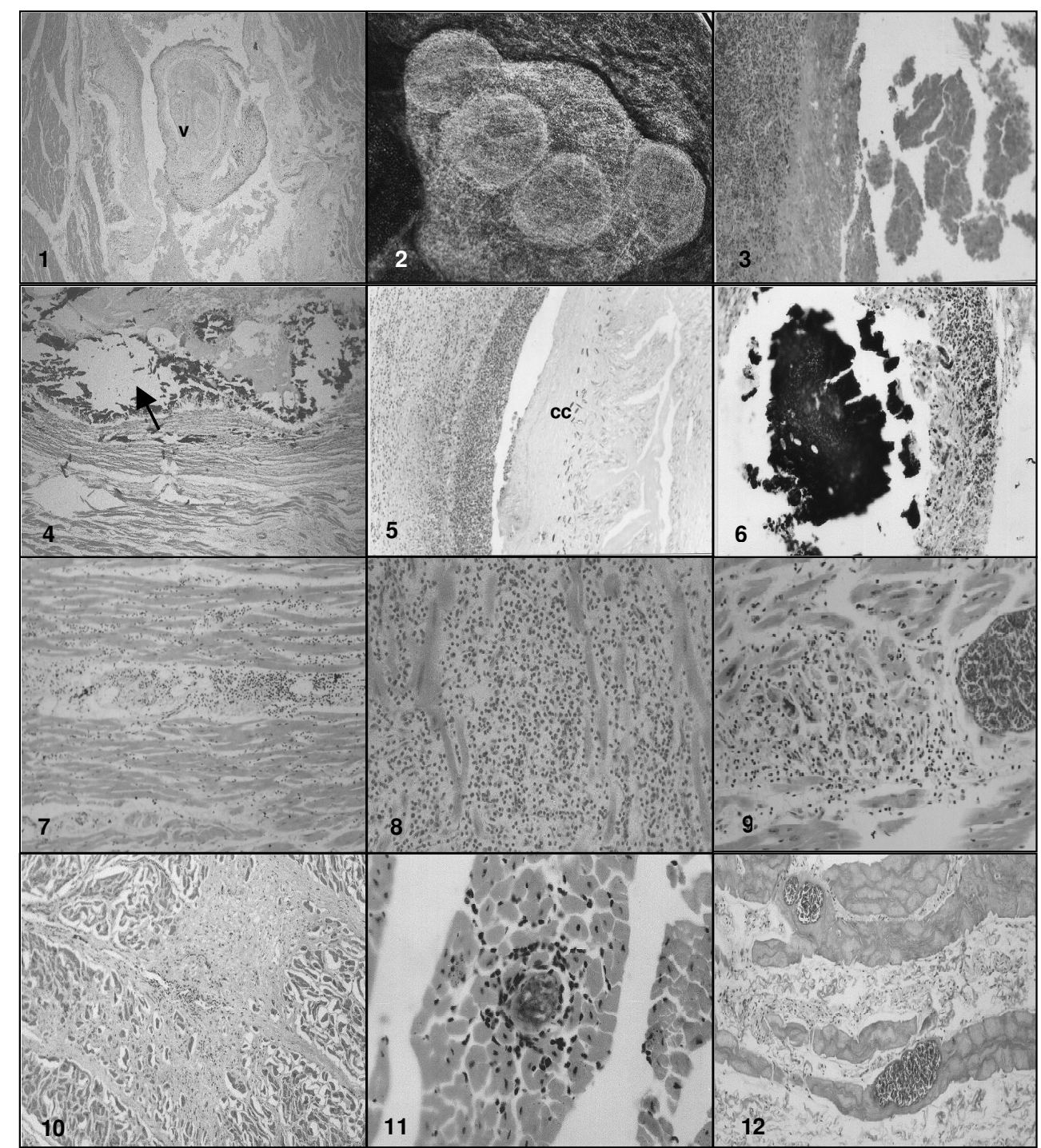

Figura 1: Bovino. Cisticerco íntegro no miocárdio. Escólex com ventosas (v) e corpúsculos calcários, contornado por cápsula fibrosa. HE, obj. 10X. Figura 2: Bovino. Coração. Escólex desarmado do Cysticercus bovis, com detalhe das ventosas, após compressão entre lâminas. Obj. 20X. Figura 3: Bovino. Coração. Necrose caseosa envolta por restos celulares. HE, obj. 20X. Figura 4 Bovino. Coração. Granuloma centralizado por material caseocalcário, envolvido por barreira de histiócitos e mineralização (seta) na cápsula fibrosa. HE, obj. 10X. Figura 5: Bovino. Coração. Granuloma constituído por infiltrado misto e restos do cestóide (material hialino acelular) com corpúsculos calcários (cc). HE, obj. 10X. Figura 6: Bovino. Coração. Lesão granulomatosa rica em células gigantes multinucleadas, com centro calcário evidenciando múltiplos corpúsculos calcários ovais, levemente basofílicos, como fendas. HE, obj.20X. Figura 7: Bovino. Miocárdio. Infiltrado difuso de mononucleares. HE, obj.10 X. Figura 8: Bovino. Miocardite crônica ativa, com raros eosinófilos, dissociando as miofibras. HE, obj. 20X. Figura 9: Bovino. Miocárdio. Lesão granulomatosa inespecífica ao lado de cisto de Sarcocystis sp. HE, obj.20X. Figura 10: Bovino. Miocardite crônica fibrosa com amiotrofia. HE, obj. 20X. Figura 11: Bovino. Coração. Cisto de Sarcocystis sp. circundado por infiltrado de mononucleares. HE, obj. $20 \mathrm{X}$. Figura 12: Bovino. Coração. Cistos de Sarcocystis $\mathrm{sp}$ nas fibras de Purkinje. HE, obj. 20X. 
macrófagos, com subseqüente fibroplasia. Isso pode explicar a ausência dos corpúsculos calcários na maioria das lesões e, inclusive, a característica granulomatosa inespecífica, rica em tecido fibroso, em algumas delas.

Outras lesões aqui observadas consistiram em áreas focais esbranquiçadas no miocárdio. Microscopicamente, tais áreas representaram miocardites inespecíficas multifocais (Figuras 7, 8 e 9), compostas por elementos celulares mononucleares, associando-se, por vezes, à infiltração gordurosa e fibrose dissociando as miofibras. Tais achados são comparáveis aos descritos por Bundza et al. (1988), em algumas lesões não mineralizadas, pequenas, acinzentadas ou esverdeadas diagnosticadas como cisticercose em bovinos. No presente trabalho, os infiltrados inflamatórios linfocitários foram observados inclusive em fibras de Purkinje. A amiotrofia por compressão devido à fibrose, extensa em alguns casos (Figura 10), provocou a destruição de miofibras (necrose). Convém ressaltar que as miocardites estiveram presentes em amostras com e sem lesões visíveis e, amiúde, foram encontradas ao redor de cistos de Sarcocystis sp (Figura 11). A esse respeito, Dubey et al. (1982) e Jones et al. (2000), citam que não há reação alguma ao redor de cistos maturos vivos a não ser quando morrem, sendo, por conseguinte, capazes de determinar inflamação. Santana et al. (2003) não evidenciaram Sarcocystis sp. macroscópicos nem tão pouco qualquer alteração patológica das miofibras, a não ser a

\section{Referências}

ACHA, P.N.; SZYFRES, B. Zoonosis y enfermidades transmisibles comunes al hombre y a los animales. 2. ed. Washington: OPAS, 1986. $988 \mathrm{p}$.

BUNDZA, A.; FINLEY, G.G.; EASTON, K.L. Na outbreak of Cysticercosis in feedlot cattle. Can. Vet. J.v. 29, p. 993-996, 1988.

COSTA, R.F.R; SANTOS, I.F.; NASCIMENTO, E.R.; TORTELLY, R. Pesquisa de cisticercose em corações de bovinos comercializados na cidade de Nova Friburo/RJ, inspecionados pelas técnicas de Santos e do fatiamento. Higiene Alimentar, São Paulo, v. 19, n. 129, p. 82-87, 2005.

CHOWDHURY, A.B.; DASGUPTA, B.; RAY, H.N. On the nature and structure of the calcareous corpuscles in Taenia saginata. Parasitology, v. 52, p. 152-157, 1962.

DUBEY, J.P.; SPEER, C.A.; EPLING, G.P. Sarcocystosis in newborn calves fed Sarcocystis cruzi sporocysts from coyotes. Am. J. Vet. Res. v. 43, n. 12, p. 2147-2164, 1982.

GIBSON, T.E. The identification of Cysticercus bovis, with special reference to degenerate cysticerci. Ann. Trop. Med. Parasit., v. 53, p. 25-26, 1959.

JONES, T.C.; HUNT, R.D.; KING, N.W. Patologia Veterinária. 6. ed. Estados Unidos: Williams and Wilkins: A Waverly Company. 2000.

KELLY, W.R. The Liver and Biliary Sistem: helmintic infections of liver and bile ducts In: JUBB, K. V. F.; KENNEDY, P. C. and PALMER, N. Pathology of Domestic Animals. 4. ed. San Diego, Cal.: Academic Press. v. 2, cap. 2, 1997. 747 p.

MONLUX, S.W.; MONLUX, A.W. Atlas of meat inspection pathology. Washington: United States Department of Agriculture, May, 1972. 178 p. PEREIRA, A.B.L. Sarcosporidiose em bovinos abatidos em Londrina (PR): I-aspectos epidemiológicos, parasitológicos e anatomopato- presença dos microcistos. Pereira (1986) por sua vez, além dos microcistos, comprovou a infiltração de linfócitos, como pequenos focos localizados no miocárdio.

Digno de nota foi a intensidade da infecção, impressionante em algumas amostras, e a presença conspícua destes cistos nas fibras de Purkinje, sem qualquer reação (Figura 12). Contudo, não se sabem quais os efeitos imputados à presença deste coccídio no sistema de condução cardíaco (Jones et al., 2000).

\section{Conclusões}

Dentre as lesões inflamatórias cardíacas, foram distinguidos um processo por parasitas e um inespecífico, multifocal.

As lesões tiveram um caráter crônico, tendo sido observadas predominância de elementos mononucleares, tais como linfócitos e macrófagos e ainda células gigantes multinucleadas, amiotrofia, mineralização e fibroplasia.

No caso da cisticercose, a possibilidade do C. bovis morto não ser identificado, principalmente em lesões crônicas (abscedadas e mineralizadas), pela escassez ou ausência dos corpúsculos calcários, conforme verificado, pode dificultar estudos nosológicos com lesões da mesma natureza.

A ocorrência de Sarcocystis sp. foi freqüente, inclusive nas fibras de Purkinje.

lógicos; II - Viabilidade do S. cruzi Hasselmann, 1926, em corações frescos e congelados de bovinos. Niterói, 1986. 89 f. Dissertação (Mestrado em Medicina Veterinária) - Faculdade de Veterinária, Universidade Federal Fluminense, Niterói. 1986.

SANTANA, V.L.A.; ALVES, L.C.; SOUTO-MAIOR, M.P.; FAUSTINO, M.A.G.; LIMA, M.M. Ocorrência de Sarcocystis (Lankester, 1882) na musculatura cardíaca de bovinos comercializados em feiras livres do município de São Lourenço da Mata - Pernambuco - Brasil. Revista Brasileira de Ciência Veterinária, v. 10, n. 1, p. 39-41. 2003.

SANTOS, I.F. Diagnóstico da cisticercose bovina em matadouros: novas técnicas de exame de esôfago e diafragma. 1984. $127 \mathrm{f}$. Tese (Doutorado em Medicina Veterinária) - Faculdade de Veterinária, Universidade Federal Fluminense, Niterói. 1984.

SANTOS, I. F. Um modelo de inspeção para a detecção da cisticercose muscular bovina em matadouros. 1993. 73 f. Tese (Concurso para Professor Titular) - Departamento de Tecnologia de Alimentos, Universidade Federal Fluminense, Niterói. 1993.

SANTOS, I F.; MANO, S.B.; TORTELLY, R.; SANTOS, M.L.S.; SILVA, D.A.S. Estudo da localização do Cysticercus bovis em corações de bovinos abatidos sob inspeção. Higiene Alimentar, São Paulo, v. 15, n. 89, p. 37-44, 2001.

STERBA, J.; DYKOVÁ, I. Tissue reaction of the skeletal muscles of cattle both to a spontaneous and experimental infection with Cysticercus bovis. Folia Parasitologica (Praha), v. 25, p. 347-354, 1978.

STERBA, J.; DYKOVÁ, I.; MACHNICKA, B. Tissue reaction in the heart of cattle with a spontaneous and artificial Cysticercus bovis infection. Folia Parasitologica (Praha), v. 26, p. 27-33, 1979.

VILLANUEVA, J.H.; PERAZA, J.H. Incidencia y localizacion de Cysticercus em bovinos sacrificados. Cienc. Tec. Agric. Veterinaria, v. 3, n. 2, p. 55-66, septiembre, 1981. 